\title{
Static/dynamic friction and wear of some selected polymeric materials for conformal tribo-pairs under boundary lubrication conditions
}

\author{
Daniel NILSSON ${ }^{1}$, Braham PRAKASH ${ }^{2, *}$ \\ ${ }^{1}$ Bosch Rexroth Mellansel AB, Mellansel, Sweden \\ ${ }^{2}$ Division of Machine Elements, Department of Engineering Sciences and Mathematics, Luleå University of Technology, Luleå, Sweden \\ Received: 13 December 2012 / Revised: 11 March 2013 / Accepted: 11 July 2013 \\ (C) The author(s) 2013. This article is published with open access at Springerlink.com
}

\begin{abstract}
This work is aimed at investigating the friction and wear performance of different polymeric materials having potential for hydraulic system components under lubricated sliding conditions against a steel counter face. A pin-on-disc test configuration was used for the experimental study. The different polymeric materials selected for these studies were commercial polyimides (PI), polyether ether ketone (PEEK), and flouropolymers. Some of these materials were bulk materials whereas others were used as coatings applied on to the cast iron substrate. The tribological characteristics of the polymers were compared with a reference grey cast iron. The frictional characteristics were evaluated in both static and dynamic conditions. The results have shown that by using polymeric materials it is possible to reduce breakaway friction by an order of magnitude compared to grey cast iron. However, the breakaway friction increased significantly after the wear tests. The polymeric materials having lowest breakaway friction have shown the highest wear with the exception of the PEEK-PTFE coating which showed low wear. PI with graphite fillers also showed low wear but it resulted in relatively high friction. The carbon fibre reinforced materials resulted in unstable friction as well as higher wear compared to the PI materials with graphite fillers.
\end{abstract}

Keywords: polymer tribology; static friction; dynamic friction and lubricated wear

\section{Introduction}

Breakaway friction is an important parameter in many lubricated applications like journal bearings and hydraulic motor components. Under steady state conditions, the operation of moving machine components is in full film lubrication or at least in mixed lubrication regime. However, during start up and at low speeds, the machine components operate in boundary lubrication regime where there is risk of high wear and friction. Polytetraflouroethylene (PTFE) and other polymers have been widely used materials to reduce breakaway friction. The drawbacks with polymers in general and PTFE in particular are their

* Corresponding author: Braham PRAKASH.

E-mail: braham.prakash@1tu.se low strength and poor wear resistance. With the use of fillers, the strength and wear resistance of polymeric materials can be significantly improved.

There are many different polymers on the market like polyimide (PI), polyetheretherketone (PEEK) and PTFE. The polymeric materials are often reinforced with fillers and used in the form of composites. Usages of these fibres increase the load carrying capacity and wear resistance of the polymeric materials. Fibre reinforcement is often used in conjunction with solid lubricant particles like $\mathrm{MoS}_{2}$, graphite or PTFE to improve the frictional properties of the composite material. Fibres can be distributed randomly in the matrix or oriented in the mould fill direction. The effect of fibre orientation on wear was studied by Cirino et al. [1], who reported that fibres oriented parallel to 
the direction of sliding resulted in lower wear. In some instances fibres can abrade the counter surface. However, in some cases this abrading effect can be beneficial because of the polishing effect on the counter surface. Newly developed composites also make use of nano particles as fillers which have the interesting feature of a large interfacial area. These nano particles based composites have been reviewed by Friedrich et al. [2]. PTFE with its low friction has been the most important polymeric material for tribological applications. The low friction is governed by the formation of a thin and oriented transfer film on to the counter face during initial sliding. An important parameter in the formation of an effective transfer film is the surface roughness of the counter surface. A smooth surface can hinder formation of transfer film and a very rough surface may lead to high wear of the polymer due to abrading action of the hard counter surface asperities. So there often exists an optimum roughness of the counter surface for desirable tribological performance of polymeric materials.

Due to their self-lubricating (low friction) properties, polymers have mostly been used in applications where the use of lubricating fluids is undesirable such as pharmaceutical and food industries. Owing to this, most of the tribological research on polymers has been carried out in dry conditions and only a very few studies under lubricated conditions have been reported.

In lubricated conditions, some studies have shown higher wear of polymers compared to those in dry conditions [3] owing to degradation of their mechanical properties due to absorption of fluid and also the limited transfer film formation in presence of a lubricant. On the contrary, some researchers have shown lower friction and wear of polymers in oil lubricated conditions compared to those in dry conditions. Dickens and co-workers [4] studied the wear and friction of polyphenylene oxide (PPO), PTFE and PEEK at different loads, speeds, and fluid viscosities. They found out that friction and wear were always higher in dry conditions even at speeds as low as $1 \mathrm{~mm} / \mathrm{s}$. At the highest tested speed of $1 \mathrm{~m} / \mathrm{s}$, wear was 3-4 orders of magnitude lower in lubricated conditions and this was attributed to hydrodynamic effects. Zhang et al. [5] reported that friction of a sintered bronze bearing with PTFE reduced by 2-3 orders of magnitude and the PV (pressure $x$ velocity) limit was also enhanced with an order of magnitude in lubricated conditions. In an earlier study, Sethuramiah et al. have reported a decrease in wear by 1-2 order of magnitude of pure PTFE under lubricated conditions compared to that in dry sliding [6]. They further opined that in case of PTFE, wear is inversely dependent on hydrodynamic effects. Choudhary [7] discussed the filler enrichment on surface during both dry and lubricated sliding of polymer composites and reported that the filler enriched layer may have a positive effect on lubricated wear.

Recently, research on PTFE based composites as replacement for babbitt material in hydro generator thrust bearings has also been carried out [8]. The breakaway friction of polymers has been studied $[9,10]$ with a view to reduce the breakaway friction of hydrodynamic journal bearings and to replace the conventional babbitt material. A soft polymer layer can be beneficial not only for starting friction but also for operation in full film regime due to the compliant property of polymers. The hydrodynamic pressure can be reduced and the oil film thickness can be increased [11]. However, the oil film temperature can increase due to lower heat transfer coefficient of polymers compared to metals.

Thin thermoset polymer coatings are interesting because of the ease in applying a polymer layer to a substrate. Some studies have been conducted on air conditioning refrigerant compressors in which the use of PEEK/PTFE and PEEK/MoS 2 resulted in low friction and wear under marginal lubrication conditions [12]. Demas and co-worker [13] studied polymeric PTFEbased coatings and found that the coatings were comparable to a diamond like carbon (DLC) coating regarding their friction and wear performance. At high loads, the polymer coatings were worn, but the wear particles worked as a third-body lubricant and were beneficial in the scuffing performance.

The understanding of friction and wear characteristics of polymer under lubricated conditions is therefore vital as most high performance hydraulic and mechanical systems involve the use of hydraulic or lubricating fluids. Conventional materials like cast iron are known to have a stable boundary friction coefficient and an important question is the stability of the breakaway friction of polymers during a wear 
process if the cast iron was to be replaced by polymeric materials. Thus the aim of this work is to investigate the lubricated friction and wear characteristics of different commercially available polymeric materials (both in bulk and coating forms) and compare them with those of a conventional cast iron material. The idea is to ascertain whether the polymers can be a good choice for conformal tribopairs such as a journal bearing which usually operate in hydrodynamic lubrication regime with some hydrostatic lift and also occasionally under boundary lubrication conditions.

\section{Experimental materials}

In this work, eight different commercial polymer materials and cast iron (as a reference material) were chosen for tribological studies. Their salient properties have been summarized in Table 1. Four of these were bulk materials and the others were used as coatings applied on to cast iron or steel substrate.

\section{Test apparatus and procedure}

Tribological studies were conducted by using a pin on disc machine under lubricated conditions. The test

Table 1 Experimental materials and their salient properties.

\begin{tabular}{|c|c|c|c|c|}
\hline $\begin{array}{c}\text { Material } \\
\text { symbol }\end{array}$ & Type & $\begin{array}{c}\text { Basic } \\
\text { material }\end{array}$ & Fillers & $\begin{array}{c}\text { Compressive } \\
\text { strength } \\
(\mathrm{MPa})\end{array}$ \\
\hline A & Bulk & Cast iron & $\begin{array}{l}\text { Graphite } \\
\text { flakes }\end{array}$ & 840 \\
\hline B & Bulk & $\begin{array}{l}\text { PFA fluoro- } \\
\text { carbon resin }\end{array}$ & $\begin{array}{l}\text { Long } \\
\text { carbon } \\
\text { fibers }\end{array}$ & $\begin{array}{c}302 \\
\text { (80 in flow } \\
\text { direction) }\end{array}$ \\
\hline $\mathrm{C}$ & Bulk & PI & Graphite & 170 \\
\hline $\mathrm{D}$ & Bulk & PI & Graphite & 145 \\
\hline $\mathrm{E}$ & Bulk & PI & $\begin{array}{l}\text { Short carbon } \\
\text { fibers }\end{array}$ & 163 \\
\hline $\mathrm{F}$ & $\begin{array}{l}\text { Coating on } \\
\text { cast iron }\end{array}$ & PEEK & $\begin{array}{l}\text { Perfluoroalkoxy } \\
\text { (PFA) }\end{array}$ & 118 \\
\hline G & $\begin{array}{l}\text { Coating on } \\
\text { cast iron }\end{array}$ & PEEK & PTFE & 118 \\
\hline $\mathrm{H}$ & $\begin{array}{l}\text { Coating on } \\
\text { cast iron }\end{array}$ & $\begin{array}{l}\text { Flouro- } \\
\text { polymer }\end{array}$ & - & - \\
\hline I & $\begin{array}{l}\text { Coating on } \\
\text { steel backing }\end{array}$ & PTFE & $\begin{array}{l}\text { Sintered } \\
\text { bronze }\end{array}$ & 250 \\
\hline
\end{tabular}

configuration for the pin-on-disc test can be seen from Fig. 1.

The upper specimens for the pin-on-disc tests were cylindrical pins of $\varnothing 4 \mathrm{~mm}$ and $3 \mathrm{~mm}$ height. The test specimen edges were rounded off with a radius of $0.2 \mathrm{~mm}$ in order to avoid edge effects. This reduced the effective diameter of the contact surface to $3.6 \mathrm{~mm}$, and the corresponding contacting surface area was $10 \mathrm{~mm}^{2}$. Specimens A-E were polished with a P400 grit polishing paper as the final finishing operation. The resulting surface roughness (core roughness) parameter $S_{\mathrm{k}}$ and flatness of the pin specimens can be seen from Table 2. In a lubricated sliding bearing, the surface roughness determines the fluid film formation. The bearing ratio curve effectively describes the tribological performance of a surface in a sliding bearing, mainly

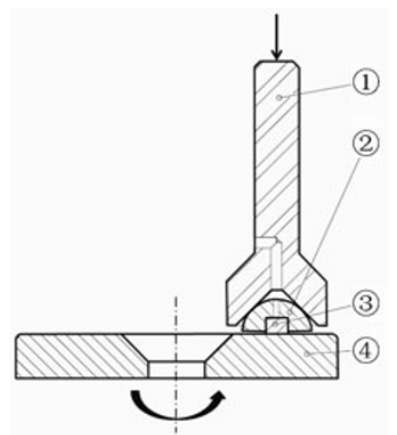

Fig. 1 Schematic of the pin-on-disc test configuration: (1) and (2) upper specimen holding arrangement, (3) upper specimen, (4) lower specimen.

Table 2 Surface characteristics of tested specimens.

\begin{tabular}{ccccc}
\hline Material & $\begin{array}{c}\text { Surface } \\
\text { finishing }\end{array}$ & $\begin{array}{c}S_{\mathrm{k}} \text { before } \\
\text { test }(\mu \mathrm{m})\end{array}$ & $\begin{array}{c}S_{\mathrm{k}} \text { after test } \\
(\mu \mathrm{m})\end{array}$ & $\begin{array}{c}\text { Flatness } \\
\text { before test } \\
(\mu \mathrm{m})\end{array}$ \\
\hline A & P400 & $1.4 \pm 0.1$ & $0.4 \pm 0.1$ & $\begin{array}{c}4-10 \text { convex } \\
\text { B }\end{array}$ \\
C & P400 & $5.8 \pm 2.6$ & $2.7 \pm 0.7$ & $4-6$ convex \\
D & P400 & $2.0 \pm 0.5$ & $1.1 \pm 0.2$ & $3-4$ convex \\
E & P400 & $3.2 \pm 1.2$ & $2.1 \pm 1.2$ & $3-5$ convex \\
F & $\begin{array}{c}\text { Blasting before } \\
\text { coating }\end{array}$ & $6.4 \pm 1.3$ & $1.4 \pm 0.2$ & $8-10$ \\
G & $\begin{array}{c}\text { Blasting before } \\
\text { coating }\end{array}$ & $3.8 \pm 0.5$ & $1.6 \pm 0.4$ & $4-6$ \\
H & $\begin{array}{c}\text { Turning before } \\
\text { coating }\end{array}$ & $6.5 \pm 5.6$ & $3.6 \pm 1.6$ & $20-30$ \\
I & - & $6.1 \pm 2.6$ & $3.3 \pm 0.9$ & $14-20$ \\
\hline
\end{tabular}


because it gives good lateral information about the surface. Because of the low hardness of polymer materials, the highest peaks, described by $S_{\mathrm{pk}}$ will not affect the tribological performance significantly. Instead, the core roughness, $S_{\mathrm{k}}$, is a better parameter to characterize the surface because this part of the surface will take most of the load when entering the mixed/boundary lubrication regime.

Despite the same polishing procedure, the resulting roughness is quite different. Smoothest surface is obtained with cast iron, closely followed by $C$ and $D$. Both $\mathrm{B}$ and $\mathrm{E}$ are composite materials with fibre reinforcements and the presence of these fibres result in relatively rougher surfaces despite the usage of the same polishing procedure as those for the other polymers. The polishing process resulted in a convex shape. Specimens F and G were sand blasted before applying the coating in order to ensure good adhesion but it also resulted in higher surface roughness values. Specimen $\mathrm{H}$ was turned before the coating process and the coating process resulted in a rough surface with cavities and low flatness. The polymer coatings F, G, and H were spray coated and cured. Specimen I was produced from a plain bearing of $\varnothing 40 \mathrm{~mm}$. It was flattened out before forming it into the shape of an upper specimen.

The cross sections of the four polymer coatings are shown in Fig. 2.
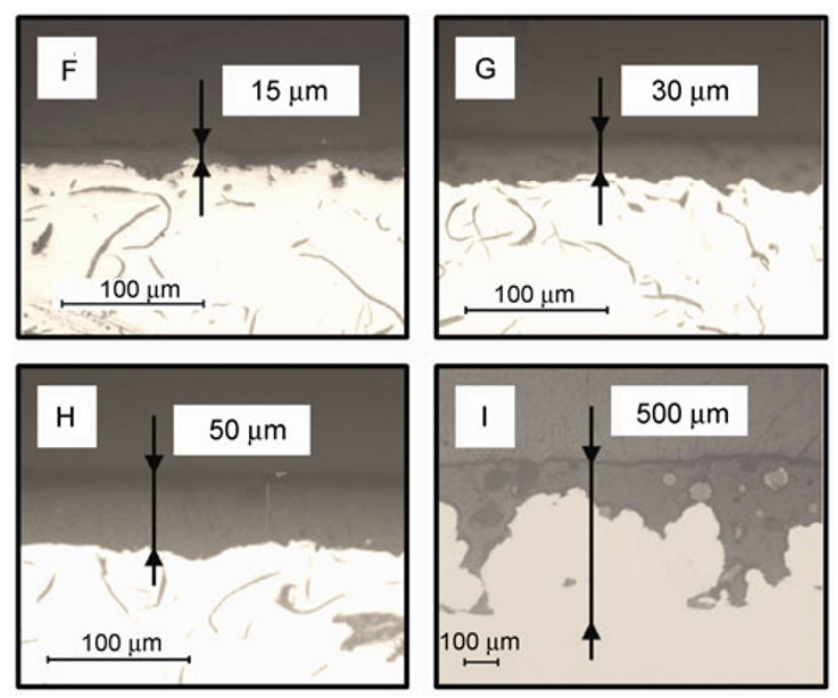

Fig. 2 Cross sections of the polymer coatings, designations according to Table 1 .
The lower specimen was a disc made of hardened $100 \mathrm{Cr} 6$ bearing steel with a hardness of $\sim 800 \mathrm{HV}$ and roughness $S_{\mathrm{k}} \sim 0.1$ and it is considerably smoother than the upper specimens. A hydraulic oil ISOVG 32 (mineral oil) containing anti-wear additive was used as a lubricant in all the tribological tests.

The conformal test used in this work has no converging gap which means that hydrodynamic effects are negligible. The speed $0.1 \mathrm{~m} / \mathrm{s}$ was intended to ensure operation in boundary lubrication regime. This was confirmed by tests at speeds varying from 0.05 to $0.2 \mathrm{~m} / \mathrm{s}$ and the friction varied only marginally. The fact that static and dynamic friction values are very close for all tested materials also indicates that operating lubrication regime was boundary lubrication. As is well known, the friction coefficients of a lubricated sliding bearing can be distinguished among full film, mixed, and boundary lubricated friction by the Stribeck curve. The friction coefficient can be as low as 0.001 in full film lubrication and it increases during transition to the mixed regime and reaches its maximum value in boundary lubrication regime. For a lubricated steel-steel contact, the boundary lubricated friction is typically $\sim 0.10$ to 0.15 . Since the static and dynamic friction coefficients in these tests are very close, it can be safely considered that the operation is in boundary lubrication regime.

As shown in Fig. 1, a half sphere was used as holder for the upper specimen to ensure an even loading of the specimen against the rotating disc. In this way, the friction force between upper and lower specimen will not tilt the upper specimen. All tests were repeated five times, but because of technical problems with the test rig, friction measurements were not correct in the first two test rounds. Therefore, only the results from the three last test rounds are presented here. To further ensure uniform loading, the coated samples were made $2 \mathrm{~mm}$ thick for the two last test rounds, which enabled the use of a flexible $1 \mathrm{~mm}$ polymer disc to be mounted on top of the specimen. The even loading could also be verified by examining the test specimens after the tests. The contact area was $10 \mathrm{~mm}^{2}$ resulting in a maximum contact pressure of $100 \mathrm{MPa}$ at $1000 \mathrm{~N}$ load.

Both the static and dynamic friction measurements using pin-on-disc test machine were done. For static 
friction measurements, a torque wrench was used to apply and gradually increase the tangential force on the specimen until sliding occurred. The torque was increased gradually during $10-20 \mathrm{~s}$ and a typical result from a static friction test is presented in Fig. 3. Typically, 4-5 breakaway tests were performed, then one minute standing still under load to see any effect of oil squeezing out of the contact. After that, another 8 to 15 breakaway tests were performed, the number of tests depending on the consistency of the obtained friction values. An average of the five highest values was taken from each test for comparing different materials.

In the dynamic tests, the lubricant was circulated and poured on top of the rotating disc. No heating device was used and the operating temperature was determined by the frictional heat generation and the ambient temperature. The bulk oil temperature at the end of the tests varied from $32-37^{\circ} \mathrm{C}$ depending on the friction heat input. An incremental loading sequence was used in which the load was increased in steps of $100 \mathrm{~N}$ to $1000 \mathrm{~N}$ in $10 \mathrm{~min}$. The sliding speed was $0.1 \mathrm{~m} / \mathrm{s}$ in all the tests.

The rotation started when the load had reached $100 \mathrm{~N}$. Duration of the test at $1000 \mathrm{~N}$ was $2 \mathrm{~h}$. All tests included a static test, a $2 \mathrm{~h}$ dynamic test and another static test after the completion of the dynamic test.

All upper specimens were weighed before and after test in order to estimate wear. The test specimens before weighing were ultrasonic cleaned in ethanol and dried for $15 \mathrm{~min}$ in an oven at $60^{\circ} \mathrm{C}$ to evaporate any absorbed fluid. The weight measurements were repeated four times for each sample to ensure

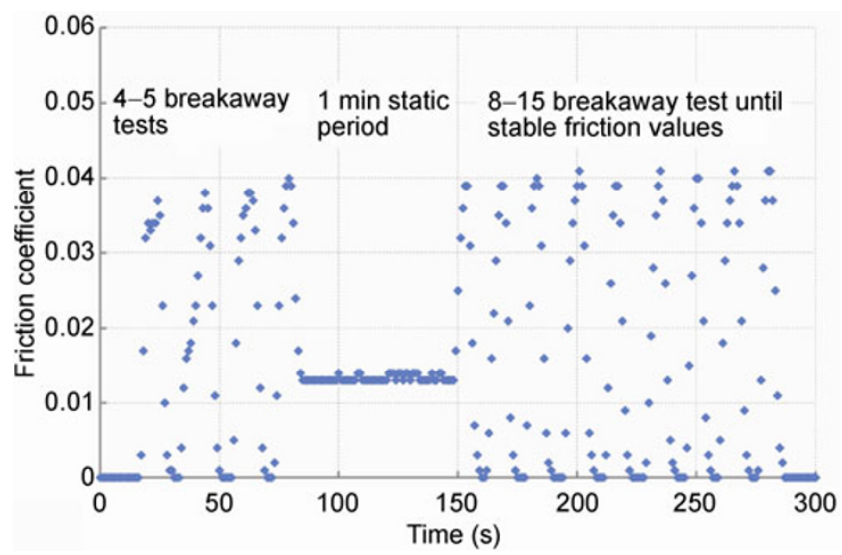

Fig. 3 Typical results from a breakaway test. reproducible results. The test specimen surfaces were also analyzed before and after tests using a 3D optical surface profiler (Wyko NT1100). The surface roughness analysis was done by using $10 \times$ and $2.5 \times$ magnifications and the analysis area was $0.6 \mathrm{~mm} \times 0.46 \mathrm{~mm}$ and $2.5 \mathrm{~mm} \times 1.9 \mathrm{~mm}$ respectively. A magnification of $10 \times$ magnification was used for calculating the core roughness $\left(S_{\mathrm{k}}\right)$ from bearing area ratio curve given in Table 2. For flatness measurement, the magnification used was $2.5 \times$.

\section{Results}

\subsection{Friction}

A dynamic friction curve for the cast iron, material A is shown in Fig. 4 as an example of a typical dynamic friction curve obtained from three test repetitions. Friction values were obtained from the curve at three different time intervals. The first value was taken at $100 \mathrm{~N}$ immediately after the start of rotation. The second value was at the end of the incremental loading when load reached $1000 \mathrm{~N}$. The third value was taken after $2 \mathrm{~h}$ wear test at $1000 \mathrm{~N}$. The dynamic friction decreases with an increase of the load from $100 \mathrm{~N}$ to $1000 \mathrm{~N}$ in $\mathrm{A}(1)$ and $\mathrm{A}(2)$ tests but an opposite behaviour has been seen in $\mathrm{A}(3)$ test. Moreover, the starting friction values at $100 \mathrm{~N}$ in $\mathrm{A}(1)$ and $\mathrm{A}(2)$ are quite different from that in $\mathrm{A}(3)$. There can be several reasons for the different starting frictional values such as variation in initial surface topographies, flatness and alignment of test specimens etc. When machining the surface of the cast iron specimen A, a slight convex shape was observed. This together with a relatively smooth surface compared to the other specimens may lead to different degree of hydrodynamic effects particularly at lo w load and consequently variation in starting friction. The very low starting friction in case of A(3) test is most likely caused due to considerably larger hydrodynamic effects compared to $\mathrm{A}(1)$ and $\mathrm{A}(2)$ tests.

The comparison of friction coefficients of the nine different materials is shown in Fig. 5. The friction coefficients are presented in relation to the static friction coefficient for material A before the wear test. There are five values of coefficients of friction for each 


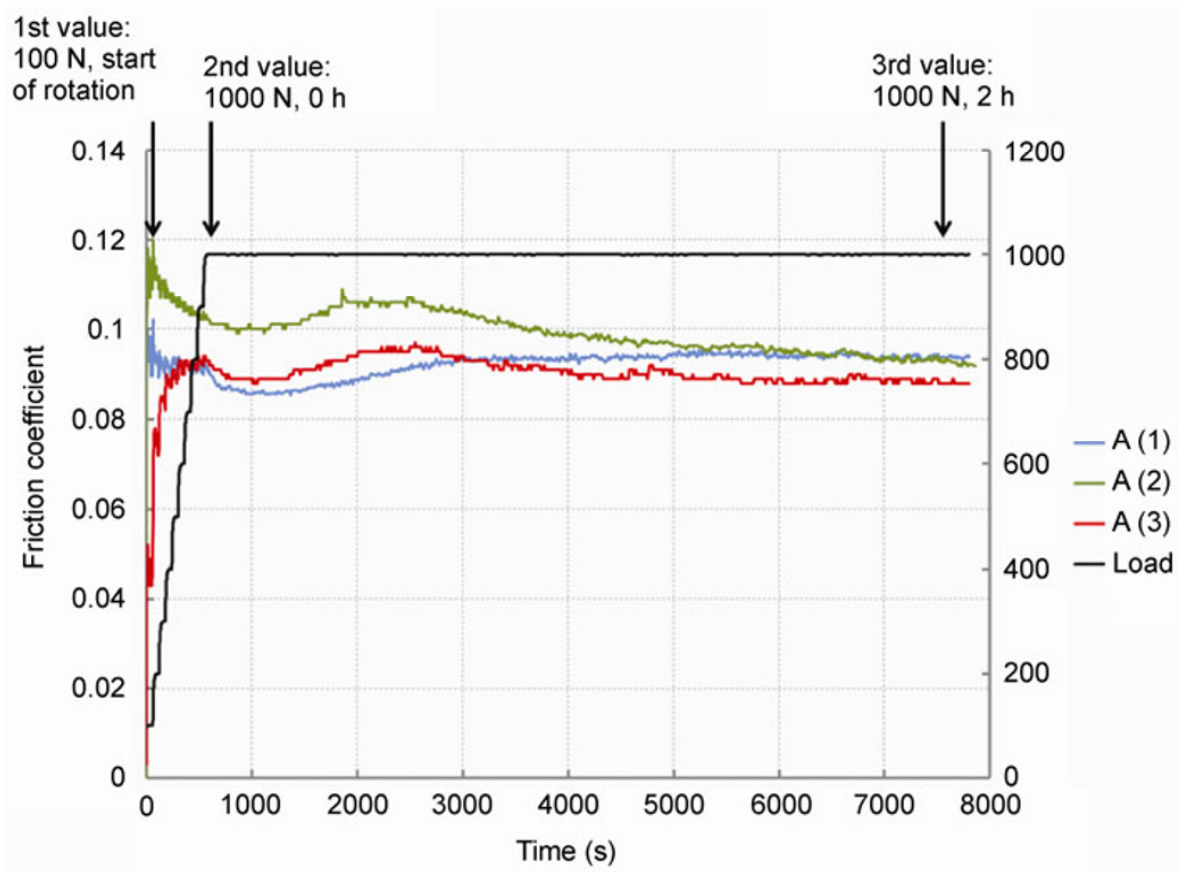

Fig. 4 Friction curve from the $2 \mathrm{~h}$ dynamic test in pin-on-disc for the cast iron specimens.

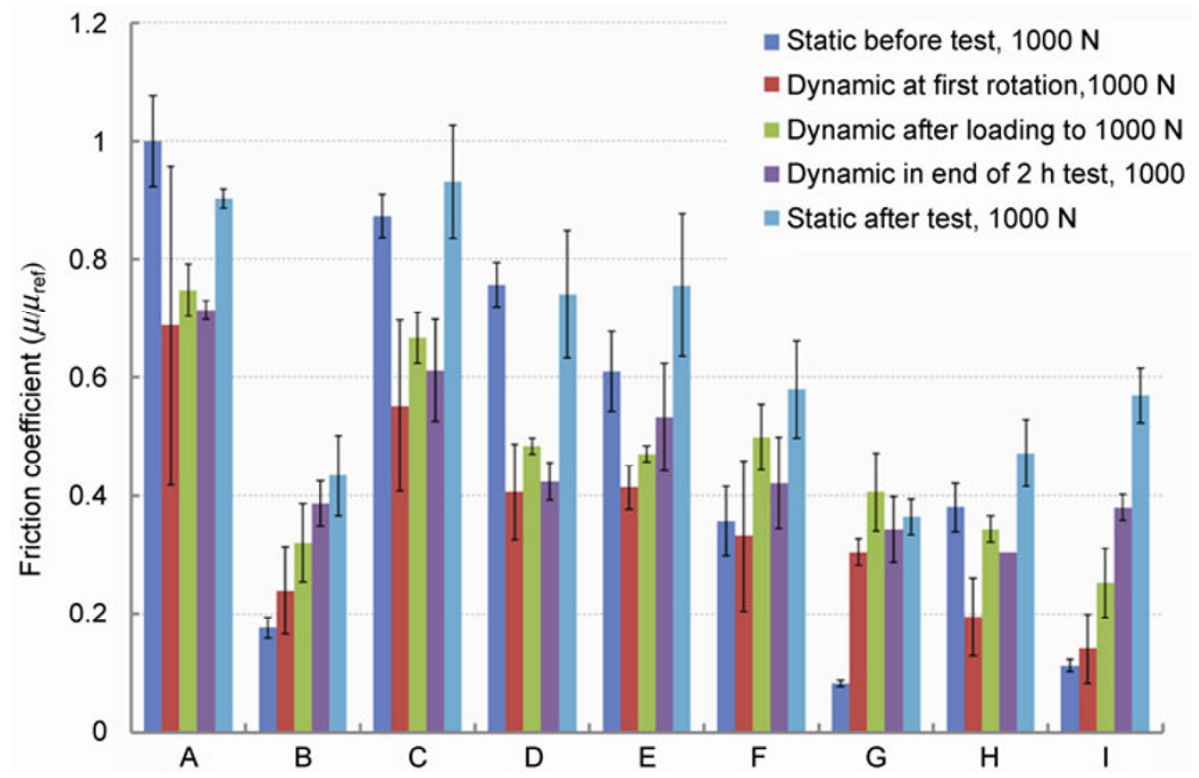

Fig. 5 Friction coefficient values in relation to the static friction coefficient for material A before wear test.

material. These are: the static coefficient of friction before the test; the dynamic coefficient of friction at $100 \mathrm{~N}$ immediately after the start of rotation; the dynamic coefficient of friction at the end of the incremental loading when load reached $1000 \mathrm{~N}$; dynamic coefficient of friction after $2 \mathrm{~h}$ wear test at $1000 \mathrm{~N}$; and the static coefficient of friction after the $2 \mathrm{~h}$ wear test. The values are mean values and the error bars are the standard deviation of the three repetitions for these tests.

The frictional behaviour of materials $\mathrm{A}, \mathrm{C}$, and D are quite similar as the static friction is equal to or slightly lower after the test compared to that before test. Also the dynamic friction at $1000 \mathrm{~N}$ is stable or slightly decreased during the test. Material E showed an increase in friction during the dynamic test and the 
static friction is also higher after the test. Material B and I have low friction before test but friction increased throughout the test. The PEEK based materials, F and $\mathrm{G}$, have higher dynamic friction than static friction but the friction during the $2 \mathrm{~h}$ wear test remained stable or decreased.

\subsection{Wear}

The analysis of wear and its quantification for different materials was done by means of a 3D optical surface profiler, an optical microscope and gravimetric measurements. In Fig. 6, the 3D surface profiles of the upper pin specimens before and after the tests are shown for four materials. The roughness marks from the production process can still be seen on surfaces of all material test specimens except B, I and E. This means that wear of most material test specimens is small and is confined to the surface asperities. Materials $C$ and D specimens behave in a similar manner and only polishing of asperities and some deeper scratches in the sliding direction have been seen. Materials F and
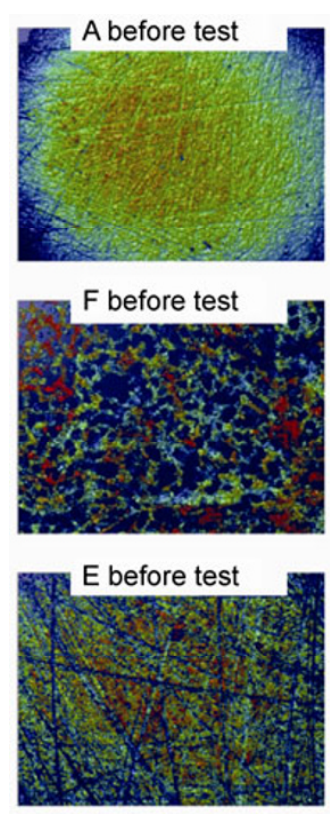

C before test

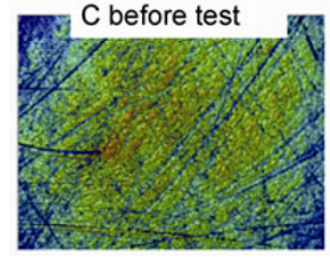

Fig. $63 \mathrm{D}$ optical profiler images of four of the tested materials (Direction of sliding is indicated with an arrow).
G specimens also behave in the same way. The rough surface from the blasting process appears to have smoothened out and a plateau surfaces with deep valleys have been formed. Material E shows higher wear and only traces of the original surface on some of the specimens can be seen.

The optical microscopic images in Fig. 7 reveal the presence of some scratches on the mating disc surface but it has almost remained unaffected after the wear test. However, in case of material $\mathrm{F}$ the mating disc has been abraded in all the five repeat tests either due to the abrading nature of the fillers or the embedded particles from the sand blasting process. These optical microscope images also show that the alignment of test specimen during the pin on disc tests was good and the load was uniformly distributed within the contact. However, in case of $\mathrm{A}$ and $\mathrm{H}$, the test specimens were not sufficiently flat to result in uniform loading. The carbon fibres are clearly visible on the surfaces of material $B$ and $E$ test specimens. On many of the polymer materials, for example C, D, E and G, deep single scratches have developed in the direction of sliding.

The quantification of wear of polymeric materials from gravimetric measurements posed some difficulties (see Fig. 8). Polymers C and D have gained weight during the tests despite the fact that the wear is low as observed by the optical surface profiler images. It seems that $C$ and $D$ both absorb fluid as these two materials show negative weight loss. Besides these (C and D), the weight loss measurements and results from optical surface profiler and optical microscopic examination indicate similar behaviour. Amongst bulk
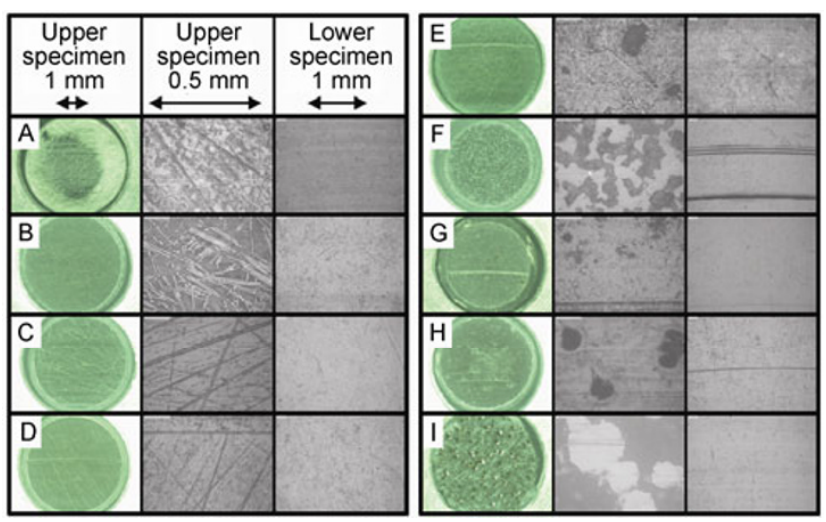

Fig. 7 Microscope images for all tested materials. 


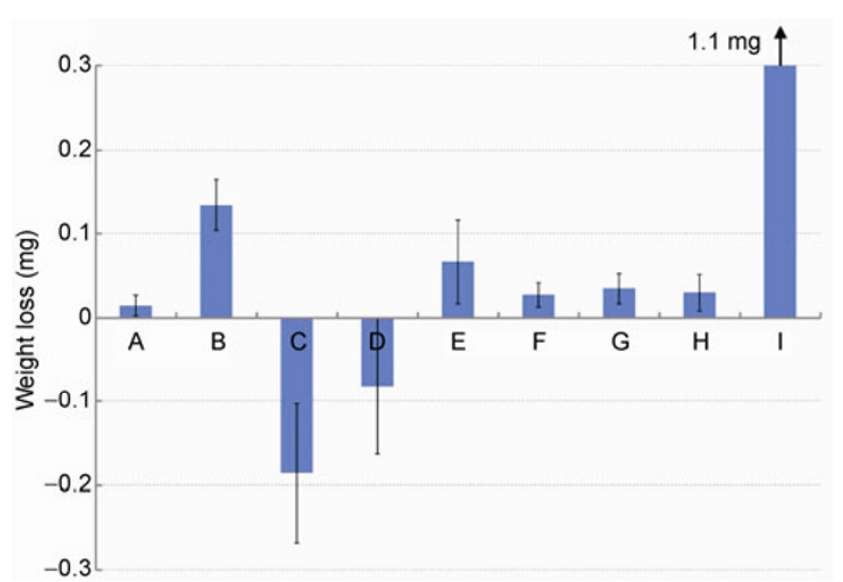

Fig. 8 Weight loss for all tested materials.

polymer, B and $\mathrm{E}$ have shown very high wear and $\mathrm{A}$ the lowest. Material I (coating) has shown the highest wear of all materials, both from gravimetric measurements and optical surface profiler analysis. The wear of the other polymer coatings (F, G, H) is low as seen from weight loss measurement results given in Fig. 8.

\section{Discussion}

All polymeric materials studied in this work except $C$ have the potential to reduce the starting friction in lubricated contacts. Materials B, G, and I appear to be most promising from the viewpoint of low starting friction for operation in boundary lubrication regime. The increase in static friction after the tests seen for $B, G$, and I is likely due to the adverse changes in the surface conditions caused by wear. It may be noted that both B and I have shown very high wear. Although, the wear in case of $G$ is not as high as that in B and I yet some wear has occurred and this might have caused surface damage that affected its starting friction after the test. The changes in surface conditions will be determined by the wear mode, type/orientation of material fillers and the nature of debris generated during the wear process.

Considering the durability aspect, materials $\mathrm{C}$ and $\mathrm{D}$ are suitable lubricated journal bearing materials in view of their very low wear. However, their starting friction would be similar or only marginally lower than that of a cast iron bearing.

The material B (containing large carbon fibers) possesses different properties in flow direction (during processing) compared to those in a direction perpendicular to flow. In the present tests, the specimens were, for practical reasons, produced with flow direction perpendicular to the sliding direction. The frictional performance of this material B is likely to be different if the flow direction was parallel to the sliding direction as indicated in Ref. [1].

Some of the materials, e.g., PEEK based materials, have higher dynamic friction than static friction. This phenomenon has also been experienced when performing the breakaway tests in which no jerky movement occurred during the start but subsequently the torque increased. This is possibly due to the composite structure of the materials.

As regards the thin polymer coating compared to a bulk polymer material, their advantage is better heat transfer. Despite similar thermal conductivities of the polymeric materials, a thin polymer layer will provide for better heat transfer owing to the higher thermal conductivity of the substrate material. The temperature measurements on top of the upper specimens during the tests using oil bath temperature of $35{ }^{\circ} \mathrm{C}$ showed that the measured temperature in the case of material $\mathrm{C}$ (in bulk form) was $35^{\circ} \mathrm{C}$ whereas it was $41{ }^{\circ} \mathrm{C}$ for $\mathrm{F}$ (as coating) despite their similar friction coefficients. This clearly indicates better heat dissipation in case of the polymeric coating. Another advantage with a polymer coating is a relatively more uniform and lower maximum operating pressure [10]. This is also evident from the present tests. With a thin soft coating on cast iron substrate, e.g., material $\mathrm{F}$, the load is evenly distributed on the whole disc as compared to that with the cast iron specimen $\mathrm{A}$, which resulted in concentrated loading in the middle of the specimen despite a very small convex form of only a few microns.

The ability to form a hydrodynamic oil film in lubricated contacts is governed by the surface roughness and conformity of the interacting surfaces. It is therefore important that a sliding bearing material is easily manufactured to a smooth surface. A close look at Table 2 shows that using the same surface preparation process, materials $\mathrm{C}$ and $\mathrm{D}$ are superior to $\mathrm{B}$ and $E$ in this respect. Further, the surface roughness and form that evolves during the running-in process is crucial for the function in a journal bearing. For satisfactory hydrodynamic performance, the surfaces 
need to be smooth and any form errors also need to be flattened out easily. The application of polymer coating to a substrate requires a relatively rougher (sand blasted) surface for good adhesion and this might result in a rough coating surface. It is also important to remember that the surface roughness in the loaded condition can be quite different from the unloaded case since polymer materials have very low Youngs moduli.

The reasons for the presence of deep scratches in polymer specimens are not very clear but could be caused by the abrading action of some extraneous particles or other hard constituents in the composite materials.

\section{Conclusions}

The tribological characteristics of eight different commercial polymer materials under lubricated sliding conditions have been studied and compared with those of the reference cast iron. The main findings of this work can be summarized as follows:

(1) The PTFE based materials have very low static friction coefficient, i.e., up to an order of magnitude lower than that of the reference cast iron at $100 \mathrm{MPa}$ contact pressure but after $2 \mathrm{~h}$ wear test the static friction increased to about $50 \%$ of the reference friction of the cast iron.

(2) PI based materials with graphite fillers are wear resistant with stable friction and may be suitable for journal bearings that continuously operate in boundary lubrication. However, their breakaway friction is equal to or only up to $20 \%$ lower than that of the reference cast iron.

(3) The friction in carbon fiber reinforced materials tends to increase as the sliding progresses and their wear is also higher as compared to those of other bulk polymers.

(4) The friction of polymer coatings tends to decrease and their wear is also low as seen from the two hours of sliding wear test.

Open Access: This article is distributed under the terms of the Creative Commons Attribution License which permits any use, distribution, and reproduction in any medium, provided the original author(s) and source are credited.

\section{References}

[1] Cirino M, Friedrich K, Pipes R B. Evaluation of polymer composites for sliding and abrasive wear applications. Composites 19: 383-392 (1988)

[2] Friedrich K, Zhang Z, Schlarb A K. Effects of various fillers on the sliding wear of polymer composites. Compos Sci Technol 65: 2329-2343 (2005)

[3] Briscoe B J, Sinha S K. Wear of polymers. Proc IMechE, Part J: J Eng Tribol 216: 401-413 (2002)

[4] Dickens P M, Sullivan J L, Lancaster J K. Speed effects on the dry and lubricated wear of polymers. Wear 12: 273-289 (1986)

[5] Zhang Z Z, Xue Q J, Liu W M, Shen W C. Tribological properties of metal-plastic multilayer composites under oil lubricated conditions. Wear 210: 195-203 (1997)

[6] Sethuramiah A, Awasthy K L, Prakash B, Mahapatra P K. Lubricated wear of PTFE and graphited PTFE. Lubr Sci 3: 181-188 (1991)

[7] Choudhary T R. Tribological investigation of heavy duty polymer based thrust pads. Ph.D thesis. New Delhi (India): Indian Institute of Technology Delhi, 2001.

[8] Simmons J E L, Knox R T, Moss W O. The development of PTFE (polytetrafluoroethylene)-faced hydrodynamic thrust bearings for hydrogenerator application in United Kingdom. Proc IMechE, Part J: J Eng Tribol 212: 345-352 (1998)

[9] McCarthy D M C, Glavatskih S B. Assesment of polymer composites for hydrodynamic journal-bearing applications. Lubr Sci 21: 331-341 (2009)

[10] Golchin A, Simmons G F, Glavatskih S B. Break-away friction of PTFE materials in lubricated conditions. Tribol Int 48: 54-62 (2012)

[11] Kuznetsov E, Glavatskih S B, Fillon M. THD analysis of compliant journal bearings considering liner deformation. Tribol Int 44: 1629-1641 (2011)

[12] Nunez E E, Yeo S M, Polychronopoulou K, Polycarpou A A. Tribological study of high bearing blended polymer-based coatings for air-conditioning and refrigeration compressors. Surf Coat Tech 205: 2994-3005 (2011)

[13] Demas N G, Polycarpou A A. Tribological performance of PTFE-based coatings for air-conditioning compressors. Surf Coat Tech 203: 307-316 (2008) 


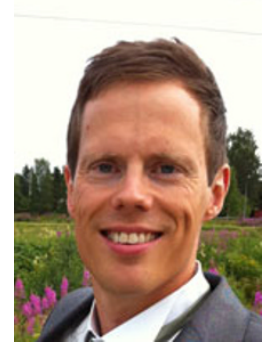

Daniel NILSSON. He obtained his MS degree from the Royal Institute of Technology, Sweden in 1998. Since then, he has been working at Bosch Rexroth (formerly Hägglunds Drives). He obtained his $\mathrm{PhD}$

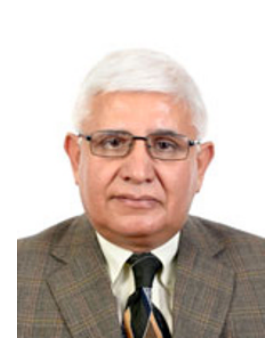

Braham PRAKASH. He obtained his MTech (Mechanical Engineering) and PhD (Tribology) degrees from Indian Institute of Technology Delhi, India. $\mathrm{He}$ is presently a professor and head of Tribolab at the Division of Machine Elements of Luleå University of Technology in Sweden since January 2002. He was a visiting researcher of Tokyo Institute of Technology (1985) degree from the Division of Machine Elements of Luleå University of Technology, Sweden in 2011. His research and development activities pertain to tribological aspects of hydraulic systems, performance evaluation, testing and analysis of tribological problems.

and fellow of Japan Society for the Promotion of Science (JSPS) at Chiba Institute of Technology (1998-2000). He has over 37 years of R\&D experience both in academia and industry in the field of tribology. His research \& teaching activities pertain to high temperature tribology, tribology of materials \& lubricants, solid lubricants/self-lubricating coatings; boundary lubrication, tribology of machine components (bearings, gears and seals), analysis of wear problems, and tribotesting. 